\title{
How Managers Experience Situations Involving Employee Mental Ill-Health.
}

\begin{abstract}
Purpose: Mental health conditions such as depression are prevalent in working adults, costly to employers, and areas of social and legal liability for employers. Line managers are crucial in implementing organizational responses to employee mental ill-health but their perspectives are largely unrepresented in literature on workplace mental health promotion. This study aimed to explore situations in which line managers became aware of, and responded to, employees' emergent mental ill-health issues in order to guide theory and practice development.

Design: Semi-structured interviews were conducted with 24 Australian managers who had supervised an employee with emerging mental health issues relating to depression or burnout. Interview transcripts were content analyzed to explore themes in managers' experiences. Findings: Managing an employee with an emerging mental health issue involves becoming aware of the issue, taking action to understand the situation and develop an action response, implementing the response and managing the ongoing situation. Each of these tasks had a range of positive and negative aspects to them e.g. managing the situation can be experienced as both a source of stress for the manager but also as an opportunity to develop greater management skills.
\end{abstract}

Practical implications: Understanding line managers' experiences is critical to successful implementation of HR policies regarding employee health and wellbeing. HR strategies for dealing with employee mental health issues need to consider implementation support for managers, including promotion of guiding policies, training, emotional support and creating a psychosocial safety climate in their work units or teams. 


\section{Introduction}

Employee health and well-being is a key focus in human resource management (HRM) due to its links with employee satisfaction and performance. Organizations are increasingly focused on employee health "not out of altruism, but as a key part of their business strategy" (Burke, 2014, p. 4) and issues associated with mental illness are recognized as requiring a strategic HRM approach (Shann, Martin and Chester, 2014). Mental illness has become a leading global health concern, estimated to affect 350 million people (World Federation of Mental Health, 2012). In Australia alone, it is estimated one in six people will experience depression in their lifetime (Australian Bureau of Statistics, 2008). Mental ill-health has an “immense" economic impact (Szeto and Dobson 2013, p. 1). Depression, in particular, has been recognized recently as the leading cause of disability (World Health Organization, 2015), has the largest individual-level effect on productivity of any health condition (Kessler et al., 2008). Depression is linked to reduced performance in areas including innovation, communication and problem solving (De Frank, 2012), and increased presenteeism, absenteeism and turnover (Cocker et al., 2011).

Accordingly, organizations need to develop policies and strategies for more effectively dealing with employee mental health issues, particularly depression. A small but growing body of research has begun to link work unit climate with employee mental health (Arnetz, Lucas \& Arnetz, 2011), requiring a greater focus on the role of line managers in the literature. Like any aspect of human resources strategy, line managers can determine the effectiveness of both implementation processes and outcomes (Woodrow and Guest, 2013).

Process evaluation literature reveals how complex the implementation of occupational health interventions can be (Biron, Karanika-Murray, \& Cooper, 2012 a \& b). Although not a lot of attention has been paid to the reasons why such interventions fail (Biron, Gatrell \& Cooper, 2010), it has been noted that the perceptions and behaviours of managers are critical 
when it comes to understanding strategies that aim to promote mental health (Biron \& Karanika-Murray, 2013).

Whilst studies have investigated the experience of employees with mental illness (e.g. Simpson, Byrne, Gabbay and Rannard, 2015), very few have explored the experiences of managers faced with an employee mental health problem (Martin, Woods and Dawkins, 2015). Extant studies that have investigated managers' and business owners' perceptions of managing employees with mental illness, have been mainly concerned with the employment of an individual with a pre-existing mental health problem at the time of employment (e.g. Shankar et al., 2014; Tse, 2004), or were very small in scale (n=5; Mizzoni and Kirsch, 2006).

A more recent study investigated managers' experiences of return to work processes of employees on sick leave due to work related stress (Ladegaard, Skakon, Elrond and Netterstrøm, 2017). Following interviews with 15 line managers with employees on workrelated stress leave, it was found that although managers acknowledged the concept of workrelated stress, most tended to focus on employee personality and individual circumstances in managing the return to work process. In addition, Lagegaard et al. (2017) reported that line managers experienced 'cross-pressure' (Murphy and Sauter, 2003), in that they struggled to navigate the opposing demands of top management's demands for efficacy and employees concerns for their own health.

While this study provided insights into managers' experiences of employee mental health, it was only concerned with managers' experiences of managing employees with stress-related conditions after they had identified a need for and taken a period of sick leave. Thus, it did not explore the challenges managers face in assisting employees to recognize that they may be experiencing mental ill-health, or in initially responding to employees who disclosure mental ill-health to the manager. Furthermore, Ladegaard et al. (2017) were 
primarily concerned with investigating the negative challenges managers face in handling return to work situations involving employees with stress-related conditions. As such, to date, there has been no exploration of the potential positive and/or rewarding aspects that arise for managers when managing employees with emerging mental health (EMH) issues.

The current paper expands our understanding of situations involving employee mental ill-health, specifically from the perspective of line managers. In doing so, it also responds to recent calls (e.g. Martin, Karanika-Murray, Biron \& Sanderson, 2014) to extend research beyond the employee level, to also consider higher levels of analysis (e.g. managers) and the interplay between different levels of analysis in relation to employee mental health. By exploring the positive and negative aspects of line managers' experiences, beyond managing the return to work process (e.g. becoming aware of the employees' mental ill-health and implementing and managing a response), HR practitioners may gain insights for preparing and supporting line managers to deal with employee mental ill-health as they emerge.

\section{Aim of the present study}

The purpose of the present study was to provide greater insight into how managers experience, and manage, situations involving employee EMH issues. The aim of the study was to guide theory and practice development by addressing one central research question and three specific sub questions:

RQ1: What comprises a manager's experience of supervising an employee with an emergent mental health issue?

RQ1a: How did the experience unfold?

RQ1b: What are the negative and/or challenging aspects of this experience for managers? RQ1c: What are the positive and/or rewarding aspects of this experience for managers? 


\section{Method}

Sample and Procedure:

The study was methodologically framed around a relativist ontological position and a constructivist epistemological stance and was consequently conducted as experiential qualitative research to explore the views, experiences and practices of managers who had the subjective experience of supervising an employee with an EMH issue (Braum \& Clark, 2013). The research focus was understanding what managers experience in such a situation, and the interpretations and perspectives they constructed about the 'positive' and 'negative' aspects of those experiences. Semi-structured interviews were used to collect data about these experiences, because they provide rich and detailed data for "understanding the lived experiences of other people and the meaning they make of that experience" (Seidman $2013 \mathrm{p}$ 9 cited in Castillo-Montoya 2016 p 812). Semi-structured interviews using broad, openended, clear and neutrally-worded questions, supplemented by prompts and follow-up questions, made it possible to "dig deep" (Turner 2010, p 758) into the idiosyncratic details of individuals experiences and achieve the goal of obtaining "relevant answers that are meaningful and useful in understanding the interviewee's perspective" (Patton 2015, p 471).

Participants were recruited from a pool of 225 managers working in Australia who responded to a survey study examining mental health issues in the workplace (Martin, 2010). Survey respondents were members of the local Chamber of Commerce and Industry and the authors' University MBA alumni. At the end of the survey, participants were asked to volunteer to be interviewed about their experiences of managing an employee with a mental health condition, by returning a written consent form providing their contact details. 24 managers responded and were subsequently interviewed for the present study. No additional inclusion or exclusion criteria were applied for participation in this study. 
As detailed in Table 1, the interview sample comprised 13 males (54\%) and $11(45 \%)$ females in the age ranges of 20-29 $(n=1), 30-39(n=9), 40-49(n=6)$ and 50-59 $(n=8)$. The types of organizations in which the managers and employees were employed at the time of the employee experiencing an EMH issue included state and federal government agencies, service providers in education, real estate, child care, transport and financial sectors, and manufacturing and pharmaceutical organizations. $58 \%$ of our interviewees worked in the private sector that that time, $33 \%$ worked in the public sector, and $7 \%$ did not specify their sector. On these three dimensions our interview sample was fairly representative of the sample for the larger survey, of which $57 \%$ were male, $43 \%$ were female, $61 \%$ were employed in the private sector and $39 \%$ were in the public sector, and eighteen different industries were represented. As the ethical approval for the interview study precluded matching of interview and survey data for interviewees, we were unable to generate data about the cultural backgrounds, educational levels, or size of employing organizations represented in the interview sample, and so cannot report how this corresponded with the survey sample. The employees they supervised with an EMH issue were working in a range of sales and customer-oriented roles (e.g. in real estate, call centers, banks and energy companies), administration roles, professional roles (e.g. lawyer, rigger) and manual occupations (e.g. truck driver, farm assistant).

The interviews were undertaken to understand what managers experienced, and how they dealt with their experiences, when supervising an employee with an EMH issue. Consequently, the interview questions investigated managers' personal experiences of supervising an employee with EMH issues related to burnout or depression by exploring: 1) how the manager became aware of the employee's issue, 2) the workplace impact of the issue, 3) how the manager responded to the situation, 4) the challenging and positive aspects of their experience, and 5) their demographic information. 
The design and focus of the study presented three imperatives for ethical conduct of the research and the management of risks to participants: 1) protection from and assistance with psychological distress that could occur when recalling scenarios related to mental illhealth, 2) privacy protection for the interviewee, the employee they supervised, and their employing organization, and 3) full disclosure of research processes and protocols to enable informed consent to participate. These imperatives were met using protocols consistent with the Australian National Statement of Ethical Research Conduct and approved by the Human Research Ethics Committee of the authors' university (Approval no: H9029). The specific strategies used to address each imperative are detailed in Table 2.

[Insert Table 2 about here]

The interviews were arranged and conducted by a specialist interviewer who was fully briefed by the lead author about the aims of the study and provided with a semi-structured interview protocol. The interviewer conducted the interviews by telephone, digitally recorded and then transcribed verbatim. Interviews took an average of 30 minutes.

\section{Data Analysis:}

Our research objective was to determine how the experience of supervising their employee unfolded for each manager so that we could construct a substantive 'pathway' theory which described the stages, contributing factors and outcomes of the managers' experiences, and that reflected the diversity of their journeys along that pathway (Richards, 2015). To achieve this we conducted a coding based thematic analysis of the interview transcripts. Thematic analysis is an analytical approach used to explore areas of commonality and distinctiveness across a dataset (Gibson and Brown 2009). Our analytical objectives were to determine 1) the different aspects of managers' experience 2) the negative/challenging aspects of this experience and 3) the rewarding/positive aspects of this experience, while also determining the elements of this experience which were 'common' to the managers we 
interviewed, and b) the elements which were distinctive and idiosyncratic. We achieved this by segmenting the data into the relevant categories, and then reviewing and re-assembling the data to develop theoretical insights (Boeije, 2010).

We initially coded the data using a system of a priori codes derived from the interview questions. Such codes provide an initial "skeleton" for a preliminary categorisation of data, which serves as a basis for further coding and exploration, and also provides an initial indication as to whether the research design is proving effective in collecting data relevant to the research focus (Gibson and Brown 2009). The a priori codes were developed to reflect the interview topics and questions, using coding rules that specified that data should be assigned to the category for the relevant interview topic by coding a) the direct response to the relevant interview question, and b) any other reference to that topic within the interview to the relevant category. Having identified and categorised the data which reflected commonalities in managers' accounts, we then applied a finer-grained analysis to identify the variations in their experiences. We reviewed the data coded into each of the apriori codes to develop "data-driven" codes (Braum and Clarke 2013) that reflected the diversity of managerial responses at each stage of the 'pathway', and about the positive and negative aspects of the experience. In this process we produced code 'families' of data categories in which each 'child' category was a specific example of the 'parent' category but differentiated from its 'sibling' categories (Gibson and Brown 2009). As an example, one manager commented they thought their employee had depression because "Some days you couldn't say anything to the person and they'd snap or they'd burst into tears, clients would come in and ask them how they were and that would be enough to set the person off and to start crying". That comment was coded to the 'family' for 'disclosure or observation' and into the specific 'child' categories for 'physical symptoms' (crying), and 'interpersonal behaviors' (snapping at people). This process produced a final system of data categories derived from and reflecting 
the original interview design but augmented to reflect the nature and range of responses captured in the interviews (see Table 3). We subsequently undertook an additional analysis of the data to determine the types of knowledge managers used and needed during their experiences and the learning needs these indicate for MBA students, which is reported elsewhere (Martin et al., 2015).

\section{[Insert Table 3 about here]}

The coding process was undertaken using the NVivo computer-assisted qualitative data analysis software (CAQDAS) program (version 10). CAQDAS programs have acknowledged strengths in supporting the creation and assignment of codes, the retrieval of data to which a given code was assigned, reviewing the original context for coded data, editing coding frameworks, and the recording of analytical processes and interpretations (Paulus Lester, \& Dempster 2014). NVivo was used in this study for its particular strengths in supporting transparent and review-able coding, which we used to audit and confirm the validity and consistency of coding decisions and interpretive conclusions. When data is coded using NVivo, a) the selected data (e.g. sentence) is hyperlinked from the source document (e.g. the interview transcript) to the data category for that code (a 'node' in the NVivo lexicon), b) a 'coding stripe' for that node is assigned to the data segment in the source document. This means that researchers can create and code exhaustively to as many nodes as they wish, and, uniquely among CAQDAS programs, create a node system which catalogues the categories and data for quick and easy retrieval, and provides a visual representation of codes, themes and sub themes developed during the analysis (Richards, 2015).

In this project the third author initially coded every interview using the coding processes described above, documenting their coding process in a coding memo and defining their coding rules in a code book (see Table 3). We opted not to have the second author replicate the coding and calculate inter-coder reliability because as Bazeley and Jackson 
(2013, p 93) have noted, "all this proves is that you can train someone [to apply the same codes to the same data], not that your codes and 'valid' or useful". Similarly, two coders can use highly similar coding approaches which are consistent with each other because they have made similarly invalid coding decisions, or been similarly inconsistent in the ways they have coded the data (Richards, 2015). According to Bazeley (2015, p 150-151), the 'litmus test' for coding quality is that "the categories developed should make sense (in the context of the project's purpose) to a second observer....and it should be evident that the data have been appropriately [coded] to the categories". To this end, the second author reviewed the node system and code book that had been created, and systematically reviewed the coding by opening the transcripts and viewing the 'coding stripes' that report all the nodes to which the data has been coded, and then by opening the nodes and reviewing all the data coded there. Whenever the validity of the coding was unclear, the second author was able to 'click through' from the coded text to the original source document to determine the context for the coded statements (e.g. the interview question being addressed, and what else was said in response and thus check the validity of the coding, in the context of the coding framework and also in the context of the original interview). All the data coded into each node was determined to be a face-valid fit with the category, but in several instances additional data was coded into the relevant node to provide more context for understanding the interviewee's response and its relevance to the category.

\section{Findings}

For the managers we interviewed, supervising an employee with an EMH issue followed a general trajectory of (1) becoming aware of the employee's mental health issue; (2) exploring the workplace implications and developing an action response; (3) implementing the response and managing it as an ongoing situation. While previous research has described the specific forms of conceptual and procedural knowledge that managers 
require in each of these phases of managing an employee with an EMH issue (Martin et al., 2015), here we describe what managers personally encountered when managing an employee with an EMH issue, including how their experiences unfolded, the positive and rewarding aspects, and the negative and challenging aspects of the experience.

As the purpose of thematic analysis is to identify themes that are "consistent phrases, expressions, or ideas that were common among research participants" (Turner $2010 \mathrm{p} \mathrm{759),}$ and the frequency with which specific themes recurred in the data should be quantified (Moreira and Costa 2016) to indicate the dominant features of the phenomena being investigated. Consequently, we have reported the numbers of managers that reported the experiences we describe below, so as to transparently indicate those that reflected "recurring messages and unifying situations" (Costa et al p 39) in the dataset and those which were atypical.

\section{Becoming Aware of the Employee's EMH Issue:}

We found that managers became aware of their employee's EMH issue in three main ways: by observing changes in the employee's workplace behaviors, through the employee's disclosure of their condition, and through complaints about the staff member.

18 managers reported that a change in the employees' workplace behavior led them to initially suspect the employee was suffering an EMH issue. Three main types of behavioral change alerted them to this possibility: changes in the employee's performance of work duties, changes in the employee's ability to cope with the workplace environment, and changes in the employee's attitude and behavior towards colleagues.

The changes in performance of work duties that served as initial indicators of an employee's EMH issue included deterioration in the quality of the employee's work, not participating in workplace activities, and a failure to complete assigned work or complete it in 
the required manner. Other indicators included fluctuations in productivity, such as Manager 107 recalling that their employee was:

"Either sort of frantically working and being incredibly productive and focused and then not coming into work and just not feeling that they could face up to being in a work environment so kind of from one extreme to another"

Managers observed changes in their employee's ability to cope with workplace environment such as increases in absenteeism and lateness, seeing their employee become unable to learn new things, and demonstrating a lack of comprehension about important issues. For some managers, these observations occurred in general workplace interactions. For others, receiving complaints about the employee from other employees or from clients caused the manager to observe the employee more closely than usual. Observed changes in the employee's attitude and emotional state, included displays of anxiety, irritability, mood swings and teariness, tiredness, a lack of focus, and dealing inappropriately with colleagues and customers.

13 managers identified that difficulties arising from the employee's interpersonal relations with the manager or co-workers and/or clients alerted the manager to potential EMH issues for the employee. Three managers observed their employees becoming aggressive or violent with the manager themselves or with co-workers or clients. As manager 114 recalled: “Whenever she's under this stress she takes it out on other individuals at work, these have manifest themselves several times through threats of violence, through to swearing at people, customers have seen her throwing things around."

Seven managers indicated that they became aware of their employees' EMH issue through direct disclosure from the employee. For four of the managers, this arose as an unprompted disclosure by the employee such as that described by manager 112 : 
"This person is quite open about it, about the medication that they're on, the fact that they get side effects with headaches and sometimes if they were having a really bad day that they would have sick leave and that helped me understand why they had a higher sick leave level than others."

For three other managers, the disclosure arose during discussions with the employee about work related issues, such as decreased performance or absenteeism, as that described by manager 125:

"I'd spoken to her a couple of times ... and she basically said to me at that point that she was recently diagnosed with depression and she had just ran out of her tablets or something and that's why she wasn't herself today"

Positive aspects of becoming aware of the employee's EMH issue

Eight managers reported that becoming aware of and investigating their employee's EMH issue generated positive outcomes in helping them gain a better understanding of mental health issues, such as that identified by Manager 125:

"I said to [my employee who told me she had depression] 'well I've never had it before can you explain to me what happens, how do you feel, what do you experience,' and so she sort of gave me a bit of a background as to how it affected her which was helpful from my perspective."

Manager 109 explained that this initial learning positively influenced her subsequent handling of the situation because:

"The symptoms [the employee] demonstrated in feeling very stressed at that time were quite pronounced but I was able to sort of keep those in mind later on and if she started to demonstrate those types of symptoms I knew there was something not quite right so it gave me an opening to discuss them with her."

Challenging aspects of becoming aware of the employee's EMH issue 
For some managers, hold conversations with their employee about the employee's mental health posed was challenging due to the manager feeling uncomfortable or under-confident when discussing such topics. Five managers acknowledged that when managing an employee with an EMH issue they felt feeling 'out of their depth' because they had a limited knowledge and understanding of mental health issues. Manager 107 provided the most detailed explanation of this challenge:

"The biggest [challenge] was kind of not understanding what she was going through...[which made me] not sure about whether the advice I was providing was appropriate.... I felt really ignorant to the whole issue and so that kind of made it a bit difficult."

Four managers said they found it difficult because they felt uncomfortable discussing personal issues, such as mental health, with their employee and/ or were concerned about the employee's emotional reaction if they did approach the subject. For some managers, these challenges were exacerbated by a lack of organizational support and insufficient guidance about the appropriate actions to take. As Manager 127 stated:

"You had no guidelines as to what to follow so you didn't know if you were interfering too far and also from an operational point of view I wasn't aware of what grounds I had to say to the staff member "oh well you're not fit to come to work so don't come"...[I] didn't know whether to say to come into work and deal with their mistakes or stand them down."

\section{Taking action to understand the employees' situation and developing an action response:}

Managers' experiences of investigating the employee's situation and determining how to respond primarily related to encouraging the employee to seek help, adjusting the employee's workplace arrangements, managing relationships with the employee's workgroup, and adjusting the manager's personal supervision style. For example, 15 
managers indicated that they actively encouraged the employee to seek professional assistance with managing their mental health issue. 11 managers encouraged their employee to seek counselling or referral to a psychologist while four managers encouraged their employee to seek medical assistance. Several managers explained that encouraging the employee to seek professional help framed their subsequent support for the employee, such as changing the employee's work schedule to accommodate counselling appointments. For some, this created an ongoing dialogue about the help the employee was receiving and the implications that had for the workplace. This was most clearly illustrated by Manager 116: "we agreed that we would meet regularly throughout the process and she came back to me a few days later and said she had been diagnosed with depression and that she would be taking anti-depressants and we talked about what allowances we may need to make for that."

\section{Implementing an Action Response and Managing the Ongoing Situation}

24 managers implemented workplace accommodations for their employee, which included changes to the employee's work schedule, work roles or work environment. 12 managers offered their employee a temporary reduction or change in work schedule, such as adjusting working hours to suit the times of day when employees felt well enough to work, or providing leave periods for the employee to have 'time out' to focus on their mental health and recovery. 10 managers made adjustments to the employee's role, such as changing job criteria and expectations, and selecting clients and tasks for the employee to handle that best suited the employee's capabilities at that time. Six managers supported their employee by asking the employee's work group to help accommodate the employee's situation, and to reduce the impact on the business, such as by sharing the employee's workload and assisting the employee during times of incapacity. 
For some managers, the experience of supporting their employee involved adjusting their personal supervision style towards the employee by adopting new behaviors or adjusting their expectations of the employee. Two managers acknowledged temporarily relaxing their performance expectations for the employee and holding back bad news to accommodate the employee's low resilience. Another six managers reported introducing regular discussions with the employee to monitor how the employee was feeling, how well the workplace accommodations were working for them and how comfortable the employee felt handling their workload.

Challenging aspects of implementing a response and managing the ongoing situation

The need to manage relationships with other employees was noted by several managers as a particularly challenging aspect of their experience, largely due to the need to protect the employee's right to privacy. As Manager 128 explained, the restrictions of confidentiality impacted the workgroup's understanding and empathy towards the employee's behaviors and performance:

“The people who weren't sort of privy to this person's personal situation weren't sort of making any allowances for that person's behavior so was sort of writing it off as just not pulling their weight, there was no empathy there for their situation so I think that sort of translates into a bit of animosity on their part and not being as supportive of someone in that situation as they could have been."

For some managers, this challenge was exacerbated by the employee's EMH issue. Tensions caused by the employee's testiness and irritability sometimes left workgroup members uncertain about whether or how to interact with the employee. In one case, the impact of the employee's EMH issue was so significant that another staff member left their job because they "couldn't tolerate the [employee's] bad moods" (Manager 115). Managers also explained that the need to re-distribute the employee's workload to other staff increased the group's 
workload and, in some cases, reduced the amount of empathy workgroup members extended towards the employee, as Manager 114 recalled:

"Initially there was support because a lot of them were aware of what had happened but I think after several weeks that support was turning into anger particularly with some of the outbursts and...some other people started to pick up parts of her work so they weren't overly happy."

Eight managers identified that managing their employee's situation created an additional challenge to manage increases in their own workload. Manager 112 explained this impact:

“Someone else would pick up some of her work and then I'd pick up some of their work so in the end everyone's workload increased including mine. Plus on top of that I had the coordination of it and the stress of "what should I be doing about this in the longer term?"

For some managers, this created an additional challenge to maintain a sense of professional distance while helping their employee deal with a personal issue. As Manager 127 explained: "Sometimes it was hard to draw the line between friend and boss. The person was trying to contact me and get support out of hours but you also still have to have a level there that 'I'm your boss and you're my staff member' so it was hard to take that step back.",

Nine managers acknowledged that when managing an employee with an EMH issue they found it particularly challenging to balance needs of their employee with the commercial needs of their organization. Some found it hard to accommodate the employees' needs in an operational sense because you didn't really know if they were going to turn up the next day or not" (Manager 121). Other managers found it difficult to determine how to factor the employee's EMH issue into evaluations of their work performance. As Manager 112 recalled: 
"I found managing work performance the most difficult because it was really hard to know whether this person just actually wasn't doing the job to the best of their ability or whether it was actually their illness that was affecting their work performance."

Eight managers identified that managing an employee with an EMH issue increased their personal stress levels due to being unsure about how best to manage the situation and being "brought down" at times by the moods of their employee. As manager 115 explained:

"Emotionally it was very distressing, it made me with sleepless nights wondering how to cope and you come back to the workplace tired, you become clouded in your judgements.....You yourself try and absorb the negative energy and you were easily triggered off....You've got to consider that your interaction with that person is actually bringing you down as well so you've got to look after yourself."

Five of these managers reported that the stress and emotional impact of managing their employee's situation impacted their personal lives. This impact was heightened by the fact they often continued to worry about the employee and the situation outside of work hours, as Manager 128 frankly recalled:

"I have to say a couple of nights I came home and sat in the shower and cried.

It's not nice to see someone suffering and it's really hard in the scheme of things.... So that is what I found difficult."

Another manager (125) spoke specifically of feeing challenged by conflicting ideas about their role in the situation:

"I felt a bit helpless because I couldn't do anything personally to fix it and I'm the fix it person, I'm in a managerial position, you're supposed to be able to fix things and it wasn't anything that I could control" 
Positive aspects of handling the ongoing situation

Eight managers reported developing new insights about positive outcomes that result from supporting an employee through an EMH issue. For three managers, these were the rewarding experience of seeing the employee recover. As Manager 107 succinctly put it:

"It was distressing seeing her distressed but also seeing her come out the other end of it was really rewarding as well."

For manager 116, this related to the positive experience of helping the employee help themselves:

"she thanked me at the end of that 3 month period, she thanked me for drawing her attention to it and she was able to sort of get over a particular issue and get on with her life."

For others, such as Manager 107, the experience also positively affected the work group "in that it brought the team closer together because it made us a more close knit team and a more supportive environment for her to get through it."

Several managers felt their experiences gave them new and positive insights into their own managerial style and capabilities, such as that recalled by Manager 128:

"I came out of it thinking 'well on balance I think I handled that really well' and I was a bit tougher than I thought I was. ...it was actually one of the very first positions I had in a supervisory role and... I realised that I was prepared to tackle things that maybe other people wouldn't have been."

For others, the experience prompted the development of new managerial skills in stress management and time management, and new capabilities in developing effective strategies for handling such situations. Six managers acknowledged they had learned that they would handle a similar situation differently in future, including specific examples such as raising the issue 
sooner with the employee and seeking assistance from Human Resources about handling the issue before approaching the employee.

\section{Discussion}

This study provides the first insights into the situations managers face in becoming aware of an employee EMH issue and developing and implementing their responses to it. Managers in this study reported that they became aware of an employee's EMH issue via changes in the employee's behaviors and attitudes, or via disclosure from the employee. In some cases the employee proactively disclosed their mental health condition to the manager, while in others that disclosure arose from conversations initiated due to concerns about the employee's performance or other behaviors at work. Some managers found that facilitating these conversations with employees helped them to develop valuable skills and insights, while others felt the need for additional training and knowledge to better handle these conversation in future. This finding aligns with previous research that found managers feel poorly prepared when managing employees experiencing physical or mental health challenges (Cunningham, James and Dibben, 2004) and underscores the importance of supporting managers who are dealing with situations involving employee mental ill-health.

Previous studies have found managers in this situation experienced 'cross pressure' in terms of managing the needs of the employee with the demands of top management and/or the commercial needs of the organization (e.g. Ladegaard et al., 2017, Shankar et al., 2014, Murphy and Sauter, 2003). A particular challenge noted in our study was the cross pressure of determining 'adequate' employee job performance, with consideration for the employee's EMH issue. Similar challenges have been noted in previous research (Shankar et al., 2014), and again highlight the importance of supporting and training managers in how to strike a balance between employer and employee needs. 
Our study identified two additional sources of cross-pressure. The first was managing the needs of the employee and the needs of other workgroup members. Most often, this related to balance the need to protect the employees' privacy with other workgroup members' desire to understand the situation, particularly when their workloads increased to support the employee and/or cover their absences when on illness-related leave. Similar challenges related to maintaining employee confidentiality while balancing the demands of the employees' co-workers have been reported in previous research (Ladegaard et al., 2017), albeit in relation sick-leave absences. While not specifically reported in this study, Ladegaard et al. (2017) found that this type of cross pressure sometimes lead managers to disclose private reasons for the employee's absence, without the permission of the employee and despite that doing so violated workplace legislation. Thus, managers need training and education to develop the skills and knowledge they need to balance the employee's right to privacy with the workgroup's need to understand why workplace accommodations are being implemented to support the employee.

The second form of cross pressure we found was in relation to managers providing support to the employee while also maintaining their own personal mental health and wellbeing. Several of the managers in this study noted the experience impacted their own mental health and wellbeing, with managers feeling 'out of their depth' and stressed, at work and in their personal lives. Although not surprising, this finding extends previous research (Ladegaard et al., 2017, Shankar et al., 2014), by explicating the potential personal impact of employee mental ill-health on managers, and highlighting the importance of ensuring that both the employee and the manager are appropriately supported by the organization. Ideally, this support would be guided by an integrated approach to workplace mental health (LaMontagne, Keegel and Vallance, 2007; LaMontagne et al., 2014), and ensure clear roles, 
responsibilities and processes for supporting employees with mental illness (Martin, Sanderson, Warnecke, Dawkins, Bartlett et al., 2017).

In addition, our study presents the first empirical findings about positive aspects of supporting an employee with mental ill-health. Managers in this study reported a range of positive elements related to new professional knowledge and insights (e.g. increased knowledge of mental illness and/or enhanced management skills and capabilities) and to personal gains. This finding is important as it not only extends understandings of managers' experiences, but could also contribute to reducing stigma in relation to employee mental health. Stigma is one of the most profound barriers to individuals with a mental illness securing and maintaining meaningful employment (Krupa, Kirsh, Cockburn and Gewurtz, 2009). As managers are at the 'frontline' of identifying and dealing with mental illness among their employees, managers attitudes towards mental illness are critical in how effectively support processes unfold (Martin and Fisher, 2014). Thus, promoting positive perceptions about managing employee mental ill-health can contribute to reducing stigmarelated attitudes (Martin et al., 2017). Moreover, they can challenge commonly held assumptions by management that "employing and supporting an individual with a mental health issue represents an act of charity" and is inconsistent with workplace needs (Krupa et al., 2009, p. 420).

\section{Theoretical contributions}

The insights we have generated into line managers' experiences of supervising an employee with an EMH issue can be integrated into the broader literature on workplace mental health promotion, and specifically, into an emerging theoretical framework for understanding psychological health in organizations, known as the Psychosocial Safety Climate (PSC). PSC is concerned with the extent to which an organization has holistic policies, practices and procedures aimed at enhancing workers' psychological health and 
safety (Dollard and Bakker, 2010). It reflects an organization's "values, attitudes and philosophy regarding worker psychological health" (Idris, Dollard, Coward and Dormann, 2012, p. 19).

Research has shown that PSC can reduce the impact of adverse workplace conditions on worker well-being (Dollard, Tuckey and Dormann, 2012) when adequate resources and support systems are provided for to appropriately manage issues related to psychological health in the workplace. A strong PSC may increase the likelihood of an employee disclosing a mental health condition and discussing necessary adjustments with their manager, as they perceive that they will receive adequate understanding and support.

The PSC framework includes a "hierarchy of control" (PSC-HOC; Bailey and Dollard, 2014) which articulates the contributions that can be made at each level of an organization to promoting a PSC. Level 3 of the PSC-HOC proposes that line managers can foster PSC by: (1) creating clear communication pathways so that employees can express concerns regarding psychological health; and (2) addressing issues in an appropriate and timely manner (Bailey et al., 2014). The question of how managers achieve this has received little attention to date, establishing a prerogative to better understand management practices when supervising an employee with an EMH issue (how they may influence the organization's PSC). Our study contributes to the PSC-HOC by identifying some of the decisions, actions and contexts through which line managers deal with issues related to their employee's psychological health.

Our study identified several ways that managers can foster communication with employees about their psychological health and, by extension, influence the PSC experienced by their staff. One is by creating conversational opportunities to discuss psychological health. The managers we interviewed achieved this by initiating discussions with their employee about their workplace behavior and performance-related issues, in which employees then 
disclosed their EMH issue. Developing and implementing support options provided subsequent conversational opportunities to talk further with employees about their situation and their support needs. Our findings also suggest managers can foster communication about employee mental health by handling conversations appropriately and sensitively, especially in the first instance. The forum and tenor of initial conversations between managers and employees about psychological health may significantly influence subsequent conversations, and thereby promote or discourage employee raising concerns about psychological health, and hence the PSC experienced by employees.

Our study also produced two findings with counterintuitive implications for fostering communication to enhance PSC. The first was our finding that managerial ignorance about mental health issues can actually enhance communication about mental health. We found that managers who felt ignorant about mental health felt less willing and less comfortable having conversations with their employees about their mental health. However, we also found that some managers used their ignorance to open communication with their employee by asking their employee to educate the manager about their condition and how it affected them. This suggests that rather than preclude conversations about mental health, lack of managerial knowledge could potentially help to foster them. Our second finding was that maintaining an employee's privacy and confidentially may both help and hinder communication about psychological issues and, by extension, the creation of a strong PSC. We found that the need to protect the employee's privacy about their EMH issue sometimes hampered managers' ability to foster communication about psychological health in their organizations as they could not explain the employee's situation and rationale for workplace changes to other organizational members. In some cases, ignorance about the employee's situation generated animosity, as the employee was perceived as 'not pulling their weight.' Thus, on the one hand, maintaining an employee's privacy can enhance future communication about 
psychological issues and the PSC if employees know their privacy will be maintained. However, on the other hand, doing so may weaken PSC if animosity about workplace accommodations arises from co-worker ignorance of the employee's situation.

The PSC-HOC emphasises that policies and procedures enable top-down transmission of organizational values and priorities regarding psychological health for line managers to enact. Thus, policies and procedures influence how line managers can implement HRM strategies as organizational agents, and contribute to the organization's PSC. Our findings show that quality and accessibility of polices significant influences this transmission and enactment process by determining how well managers understood their parameters for action. This suggests that exploring more fully how policies and procedures influence the provision of a PSC is warranted.

\section{Practice implications}

A deeper understanding of what managers experience in these situations, can contribute to the creation of work climates that are mentally healthier for workers and management in several ways. First, we found that the availability (and quality) of organizational policies, guidelines and procedures affected managers' capacity to identify, select and implement appropriate workplace accommodations for their employees.

Consequently, HR managers could enhance managers' ability to deal with this demand by providing clearly defined, accessible and well promoted policies and procedures as a useful guide to action.

Our findings about the challenges managers experienced when developing workplace accommodations suggest such policies should include, at minimum, guidance about investigating employee needs, options for workplace accommodations, and processes for developing and documenting support plans for employees. Enhancing organizational communication by providing regular updates to line managers about occupational mental 
health policies would help them remain salient and useful to managers. We also suggest that collecting feedback from line managers and other relevant personnel about the usefulness of organizational policies and accommodations could enable bottom-up organizational learning about how to better support employees with EMH issues in the organization.

Second, we identify manager training as an important part of developing a strategic HRM approach to mental health. We have detailed elsewhere recommendations for designing formal management education programs such as MBA curricula (Martin et al., 2015). Shann et al (2014) conducted a training needs analysis for workplace mental health management with leaders and human resource professionals which suggests skills and content. We direct readers to these sources for further information on the design of training programs in this area.

In addition to preparing and supporting line managers for the job demand of supporting employee mental health, organisation development processes could help to improve PSC by building up the four elements which principally underlie it: 1) demonstrating senior management support and commitment to employee psychological health and wellbeing, 2) signaling that employee psychological health is a management priority, 3) demonstrating organizational communication and 4) organizational participation and involvement in education and training opportunities pertinent to employee psychological health (Idris et al., 2012).

Finally, we suggest that HR managers should provide ongoing support to managers supervising an employee with an EMH issue so as to help reduce managers' feelings of isolation and being 'out of their depth' in such situations. Support strategies may include regularly 'checking in' with the manager, providing opportunities for them to debrief about their experiences, or even referring the manager to Employee Assistance Programs (EAPs) or though close collaboration with occupational health services for professional support and 
guidance. Encouraging self-monitoring and reflective practice may also help to minimize any negative aspects of managers' experience and maximize opportunities for positive outcomes. The 'squeezing' of managers between top-management and employees we described in some situations might be avoided with regular and systematic focus on improving the psychosocial work environment and conducting screening for mental health problems (both personal and work related) to maximise early intervention. The stigma of mental illness also remains an ongoing challenge to be overcome in organisations and the role of managers in achieving this has been noted (Martin, 2010).

\section{Limitations and future research directions}

Our findings reflect the experiences of 24 managers who supervised employees with burnout or depression while operating within Australian legislative, cultural and workplace norms around mental health and its management in the workplace. Future research is needed to determine whether other managers, and managers in other countries, report similar (or dissimilar) experiences, and to investigate how these might be affected by the contexts in which they operate. Future studies should also explore how managerial experiences might differ when supervising employees with other forms of mental health issues.

Asking managers to recount their past experiences means selective recall may have affected our findings. Using longitudinal designs, experience sampling or diary methodologies in future studies would facilitate examination of managerial experiences as they unfold, thus allowing closer investigation of real time experiential learning processes, including critical incidents, perceived mistakes, and relevant personal or situational characteristics.

Managers in our study may have been motivated to participate by particularly positive or negative experiences of managing an employee with mental ill-health. Thus, future studies should employ more systematic sampling approaches to explore whether the individual 
characteristics of managers affect the experiences reported. Previous research has found that personal experience of mental ill-health (Martin and Fisher, 2014) and gender (King et al, 2012; Shann et al., 2014) influence stigmatizing attitudes towards people with depression. This suggests these characteristics may influence how managers recognise and respond to situations involving employee mental ill-health.

Future studies could usefully extend our findings by exploring both managerial and employee experiences. As our study only explored managerial perspectives, we could not determine how the approaches reported by managers affected employees or the PSC they experienced. Future studies which explore both perspectives would enable deeper exploration of both issues. Additionally, studies could examine whether the quality and dynamics of the managerial-employee relationship influence the management of employee mental ill-health and the provision of PSC. Previous research has found leader-member exchange (LMX) to be meaningfully related to employee wellbeing, depression and affective wellbeing (Sparr and Sonnentaag, 2008) and influences the resources and support that managers provide to employees. Consequently, LMX quality could influence the willingness of the employee to discuss their mental health with their manager and the support the manager is willing to provide to a given employee, directly influencing the organization's PSC. Similarly, our findings also have potential relevance to theories of the employee-organizational relationship (Coyle-Shapiro and Shore, 2007) by exploring how managers consider and enact organizational interests in this situation.

Future research should also investigate if and how managers' supervision of employees with EMH issues differs in organizations that are objectively characterized as having poor or excellent PSC. Our study did not specifically explore the extent to which workplace factors produced or exacerbated mental health issues for employees. Our findings about the contextual influences managers reported suggest it would be profitable to explore 
more fully how working conditions and approaches to preventing stress (see LaMontagne et al, 2014) might affect how managers' respond to EMH issues. One potentially important contextual factor not explored in this study is the level of resourcing (both human and financial) that managers could access to support job accommodations so that workload impacts on managers and team members are minimized.

\section{Conclusions}

By exploring the ways in which managers experienced situations involving employee mental ill-health, this study has made important contributions to theory and practice in an increasingly important area of HRM and occupational health strategy. Managers play a key role in promoting a strong PSC in their organizations, an optimal approach to simultaneously reducing the risk of mental ill-health and responding effectively when problems do inevitably arise. Considerable scope for future research in this area has been identified, providing both scholars and practitioners with new insights. 


\section{References}

Arnetz, B. B., Lucas, T., and Arnetz, J. E. (2011), "Organizational climate, occupational stress, and employee mental health: Mediating effects of organizational efficiency". Journal of Occupational and Environmental Medicine, 53(1), 34-42.

Australian Bureau of Statistics (2008), "National survey of mental health and wellbeing: Summary of results 2007, Cat. No. (4326.0), Canberra: ABS, Australia.

Bailey, T. S. and Dollard, M. F. (2014), "Psychosocial hazard management and the psychosocial Safety Climate Hierarchy of Control (PSC-HOC)”, In Dollard, M. F. and Bailey, T. S. (Eds.), Australian Workplace Barometer: Psychosocial safety Climate and Working Conditions in Australia, Academic Press Australia, Samford Valley, Australia, pp. 89-110.

Bailey, T. S., Pignata, S., and Dollard, M. F. (2014), "Programmes and interventions for psychosocial risk and worker well-being; the psychosocial safety climate (PSC) framework", In Burke, R. J. and Richardsen, A. M. (Eds.), Corporate Wellness Programs: Linking Employee and Organizational Health, Edward Elgar, Cheltenham, United Kingdom, pp. 101-119.

Bazeley, P. (2015), Qualitative data analysis. Sage: London.

Bazeley., P. \& Jackson, K. (2013). Qualitative data analysis with NVivo, (2 ${ }^{\text {nd }}$ ed). Sage: London.

Biron, C., \& Karanika-Murray, M. (2013). Process evaluation for organizational stress and well-being interventions: Implications for theory, method, and practice. International Journal of Stress Management, (Special issue). doi: 10.1037/a0033227

Biron, C., Gatrell, C., \& Cooper, C. L. (2010), “Autopsy of a failure: Evaluating process and contextual issues in an organizational-level work stress intervention". International Journal of Stress Management, 17(2), 135-158. 
Biron, C., Karanika-Murray, M., \& Cooper, C. L. (2012a), Improving organizational interventions for stress and well-being: Addressing process and context. London: Routledge.

Biron, C., Karanika-Murray, M., \& Cooper, C. L. (2012b), “Organizational stress and wellbeing interventions: An overview”. In C. Biron, M. Karanika-Murray, \& C. L. Cooper (Eds.), Improving organizational interventions for stress and well-being: Addressing process and context (pp. 1-17). London: Routledge.

Boeije, H. R. (2010), Analysis in qualitative research, Sage, London.

Braun, V., and Clarke, V. (2013), Successful qualitative research: A practical guide for beginners, Sage, London.

Burke, R. J. (2014), “Corporate wellness programs: An overview”, In Burke, R. J. and Richardsen, A. M. (Eds.), Corporate Wellness Programs: Linking Employee and Organizational Health, Edward Elgar, Cheltenham, pp. 3-27.

Castillo-Montoya, M. (2016). Preparing for interview research: The interview protocol refinement framework. The Qualitative Report, 21(5), 811-831. Retrieved from http://nsuworks.nova.edu/tqr/vol21/iss5/2

Cocker, F., Martin, A. J., Scott, J., Venn, A., Otthal, P., and Sanderson, K. (2011), “Factors associated with presenteeism amongst employed Australian adults reporting lifetime major depression with 12 month symptoms", Journal of Affective Disorders, Vol. 135 No. 1-3, pp. 231-240.

Costa, C., Breda, Z., Pinho, I., Bakas, F., \& Durão, M. (2016). Performing a thematic analysis: An exploratory study about managers' perceptions on gender equality. The Qualitative Report, 21(13/Special Issue), 34-47. Retrieved from http://nsuworks.nova. edu/tqr/vol21/iss $13 / 4$

Coyle-Shapiro, J. A. and Shore, L. (2007), “The employee-organization relationship: Where 
do we go from here?" Human Resource Management Review, Vol. 17 No. 2, pp. 166179.

Cunningham, I., James, P., and Dibben, P. (2004), “Bridging the gap between rhetoric and reality: line managers and the protection of job security for ill workers in the modern workplace”, British Journal of Management, Vol. 15, pp. 273-290.

De Frank, R. S. (2012), “Teaching a comprehensive course on stress and work”, Journal of Management Education, Vol. 36 No. 2, pp. 143-165.

Dollard, M. F. (2012), "Psychosocial safety climate: A lead indicator of workplace psychological health and engagement and a precursor to intervention success", In Biron, C., Karanika-Murray and, M. and C. Cooper (Eds.), Improving Organizational Interventions for Stress and Well-being: Addressing Process and Context, Routledge, East Sussex, pp. 77-101.

Dollard, M. F., and Bakker, A. B. (2010), "Psychological safety climate as a precursor to conducive work environments, psychological health problems, and employee engagement", Journal of Occupational and Organizational Psychology, Vol. 83 No. 3, pp. 579-599.

Dollard, M. F., Tuckey, M. R., and Dormann, C. (2012), "Psychological safety climate moderates the demand-resource interaction in predicting workgroup distress", Accident Analysis and Prevention, Vol. 45 No. 1, pp. 694-704.

Gibson, WJ \& Brown, A. (2009). Working with Qualitative Data. Sage: London. Idris, M. A., Dollard, M. F., Coward, J., and Dormann, C. (2012), "Psychosocial safety climate: Conceptual distinctiveness and effect on job demands and worker psychological health", Safety Science, Vol. 50 No. 1, pp. 19-28.

Kessler, R. C., White, L. A., Birnbaum, H., Qiu, Y., Kidolezi, Y., Mallett, D., et al. (2008), "Comparative and interactive effects of depression relative to other health problems on 
work performance in the workforce of a large employer", Journal of Occupational and Environmental Medicine, Vol. 50 No. 7, pp. 809-816.

King, E. B., Botsford, W., Hebl, M. R., Kazama, S., Dawson, J. F., and Perkins, A. (2012), "Benevolent sexism at work: Gender differences in the distribution of challenging developmental experiences”, Journal of Management, Vol. 38, pp. 1835-1866.

Krupa, T., Kirsh, B., Cockburn, L., and Gewurtz, R. (2009), "Understanding the stigma of mental illness in employment”, Work, Vol. 33, pp. 413-425.

Ladegaard, Y., Skakon, J., Elrond, A. F., and Netterstrøm, B. (2017), "How do line managers experience and handle the return to work of employees on sick leave due to workrelated stress? A one-year follow up study", Disability and Rehabilitation, advanced online publication, doi: 10.1080/09638288.2017.1370733

LaMontagne, A. D., Keegel, T., and Vallance, D. (2007), "Protecting and promoting mental health in the workplace: Developing a systems approach to job stress", Health Promotion Journal of Australia, Vol. 18, 221-228.

LaMontagne, A. D, Martin, A., Page, K., Reavley, N. J., Noblet, A. J., Milner, A. J., Keegel, T. and Smith, P. M. (2014), "Workplace mental health: Developing an integrated intervention approach", BMC Psychiatry, Vol. 14, No. 131, pp. 1-11.

Martin, A., and Fisher, C. (2014), “Understanding and improving managers' responses to employee depression", Industrial and Organizational Psychology: Perspectives on Science and Practice, Vol. 7 No. 2, pp. 270-274.

Martin, A., Karanika-Murray, M., Biron, C. \& Sanderson, K. (2014). The psychosocial work environment, employee mental health and organizational interventions: Improving research and practice by taking a multilevel approach. Stress and Health, doi:10.1002/smi.2593

Martin, A., Woods, M., and Dawkins, S. (2015), "Managing employees with mental health 
issues: Identification and conceptual and procedural knowledge for development within management education curricula", Academy of Management Learning and Education Vol 14 No. 1, pp. 50-68.

Martin, A., Sanderson, K., Warnecke, E., Dawkins, S., Bartlett, L., et al. (2017), “An integrated approach to workplace mental health", available at http://www.utas.edu.au/work-health-wellbeing (accessed 20 February 2018).

Mizzoni, C., and Kirsh, B. (2006), "Employer perspectives on supervising individuals with mental health problems", Canadian Journal of Community Mental Health, Vol. 25 No. 2, pp. 193-206.

Moreira, A., \& Costa, A. P. (2016). Introduction: Qualitative analysis: Quantifying quality and qualifying quantity. The Qualitative Report, 21(13/Special Issue), 1-5. Retrieved from Retrieved from http://nsuworks.nova.edu/tgr/vol21/iss13/1

Murphy, L. R., and Sauter, S. L. (2003), “The USA perspective: Current issues and trends in the management of work stress", Australian Psychologist, Vol. 38, pp. 151-157.

Patton, M. Q. (2015). Qualitative research \& evaluation methods (4th ed.). Thousand Oaks, CA: Sage.

Paulus, T.M., Lester, J.N and Dempster, P.G. (2014). Digital tools in qualitative research. Thousand Oaks, CA: Sage.

Richards, L. (2015). Handling qualitative data: a practical guide, (3 $3^{\text {rd }}$ ed), Sage: London.

Shann, C., Martin, A., and Chester, A. (2014), "Identifying the learning needs of organizational leaders in relation to mental health in the workplace", Asia Pacific Journal of Human Resources, Vol. 52 No. 3, pp. 298-315.

Shankar, J., Liu, L., Nicholas, D., Warren, S., Lai, D., Tan, S., et al. (2014). 'Employers' perspectives on hiring and accommodating workers with mental illness", SAGE Open, online publication, doi: $10.1177 / 2158244014547880$ 
Simpson, G. W., Byrne, P., Gabbay, M. B., and Rannard, A. (2015), "Understanding illness experiences of employees with common mental health disorders", Occupational Medicine, Vol. 65, pp. 367-372.

Sparr, J. L., and Sonnentag, S. (2008), "Fairness perceptions of supervisor feedback, LMX, and employee well-being at work", European Journal of Work and Organizational Psychology, Vol. 17 No. 2, pp. 198-225.

Szeto, A. C. H., and Dobson, K. S. (2013), "Mental disorders and their association with perceived work stress: An investigation of the 2010 Canadian community health survey", Journal of Occupational Health Psychology, Vol. 18 No. 2, pp. 191-197.

Tse, S. (2004), "What do employers think about employing people with experience of mental illness in New Zealand workplaces?” Work, Vol. 23 No. 3, pp. 267-274.

Turner, D. W. (2010). Qualitative Interview Design: A Practical Guide for Novice Investigators. The Qualitative Report, 15(3), 754-760. Retrieved fromhttp://nsuworks.nova.edu/tqr/vol15/iss3/19.

Woodrow, C., and Guest, D. E. (2014), "When good HR gets bad results: Exploring the challenge of HR implementation in the case of workplace bullying", Human Resource Management Journal, Vol. 24 No. 1, pp. 38-56.

World Federation of Mental Health (2012), "Depression: A global crisis", available at: http://www.who.int/mental_health/management/depression/wfmh_paper_depression_w mhd_2012.pdf (accessed 11 September 2017).

World Health Organization (2015), "Depression: A global public health concern", available at: http://www.who.int/mental_health/management/depression/who_paper_depression_wf mh_2012.pdf (accessed 11 September 2017). 